Madrygal. Revista de Estudios Gallegos

ISSN: $1138-9664$

\title{
As voces da (des)cortesía en galego L2: aspectos sociodiscursivos ${ }^{1}$
}

\author{
Laura Castro Lorenzo ${ }^{2}$
}

Recibido: 16 de xullo de 2019 / Aceptado: 15 de abril de 2020

\begin{abstract}
Resumo. No presente artigo reflexionaremos sobre o fenómeno da cortesía e da descortesía pragmática en relación a un grupo de estudantes de galego L2, todos procedentes de fóra da Galiza, para entendermos como estes a perciben, a constrúen e a performan. Para isto, analizaremos mostras de entrevistas semidirixidas que realizamos con algúns discentes da Escola Oficial de Idiomas de Santiago de Compostela. Exporemos, nos puntos 1 e 2, unha serie de consideracións previas que nos pareceron necesarias para introducir o lector no contexto, empírico e epistemolóxico, en que este traballo se desenvolve. Seguidamente, nun primeiro bloque informativo (sección 3), após expormos algunhas das máis relevantes concepcións teóricas dos estudos da (des)cortesía (3.1), prestaremos atención ás narrativas metapragmáticas dalgúns dos informantes, tentando tratar os aspectos normativos relativos ao fenómeno da (des)cortesía dun punto de vista sociodiscursivo (3.2, 3.3 e 3.4). Na segunda parte do artigo (sección 4), alén de explorarmos a relación teórica entre as nocións de imaxe e identidade (4.1), analizaremos mostras do corpus coa axuda destes dous marcos interpretativos coa finalidade de esclarecer como, quer a vulnerabilidade á imaxe (4.2), quer a variación lingüística e sociocultural, ben como distintos tipos de discursos identitarios (4.3) median na negociación dos roles comunicativos vinculados á (des)cortesía pragmática en situacións de contacto intercultural.
\end{abstract}

Palabras chave: cortesía; descortesía; galego L2; imaxe; identidade; comunicación intercultural.

\section{[es] Las voces de la (des)cortesía en gallego L2: aspectos sociodiscursivos}

Resumen. En el presente artículo reflexionaremos sobre el fenómeno de la cortesía y la descortesía pragmática con relación a un grupo de estudiantes de gallego L2, todos ellos procedentes de fuera de Galicia, con el objetivo de entender como estos la perciben, construyen y performan. Para ello, analizaremos muestras de entrevistas semidirigidas realizadas a discentes de la Escuela Oficial de Idiomas de Santiago de Compostela. Expondremos, en los puntos 1 y 2 , una serie de consideraciones previas que nos parecieron necesarias para introducir al lector en el contexto, empírico y epistemológico, en el que este trabajo se desarrolla. A continuación, en un primer bloque informativo (sección 3), luego de repasar algunhas de las concepciones teóricas de los estudios sobre la cortesía (3.1), prestaremos atención a las narrativas metapragmáticas de algunos de los informantes, intentando abordar los aspectos normativos relativos al fenómeno de la (des)cortesía desde un punto de vista sociodiscursivo. En la segunda parte del artículo (sección 4), además de explorar la relación teórica entre las nociones de imagen e identidad (4.1), analizaremos muestras del corpus con la ayuda de estos dos marcos interpretativos con el fin de esclarecer como, ya sea la vulnerabilidad a la imagen (4.2), ya sea la variación lingüística y sociocultural, así como distintos tipos de discursos identitarios (4.3), median en la negociación de los roles comunicativos vinculados a la (des)cortesía pragmática en situaciones de contacto intercultural.

Palabras clave: cortesía; descortesía; gallego L2; imagen; identidad; comunicación intercultural.

\section{[en] The Voices of (Im)Politeness in Galician L2: Socio-Discursive Issues}

Abstract. In this article, we reflect on how a group of Galician L2 students, all of them coming from outside Galicia, understand, perform and build pragmatic politeness and impoliteness. In this regard, we examine a series of semi-directed interview samples, conducted with students of the Official Language School (Escola Oficial de Idiomas) in Santiago de Compostela. Some preliminary considerations, intended to introduce the reader to the empirical and epistemological context in which this work was developed, are exposed in the first two sections. Then, in the first information block

1 Realizado no ámbito do Traballo de Fin de Mestrado contemplado no Mestrado Universitario de Profesorado de Educación Secundaria Obrigatoria e Bacharelato, Formación Profesional e Ensinanza de Idiomas. Universidade de Santiago de Compostela.

2 Universidade de Santiago de Compostela. Departamento de Lingua e literatura españolas, Teoría da Literatura e Lingüística xeral.

Correo-e: laura.castro.lorenzo@rai.usc.es; https://orcid.org/0000-0003-2494-9950. 
(section 3), after reviewing some of the most important theoretical approaches to (im)politeness, we focus on some informants' metapragmatic narratives, trying to address the normative aspects related to the (im)politeness phenomenon from a socio-discursive point of view (3.2, 3.3 e 3.4). In the second part of this article (section 4), we explore the theoretical relationship between the concepts of face and identity (4.1) and analyze excerpts from the corpus relying on these interpretative frameworks, in order to establish the impact of face vulnerability (4.2), linguistic and sociocultural variation and different kinds of identity discourses (4.3) on the negotiation of relational roles related to the pragmatic (im)politeness in intercultural contact situations.

Keywords: Politeness; Impoliteness; Galician L2; Face; Identity; Intercultural communication.

Sumario. 1. Introdución. 2. Consideracións previas. 3. As voces da (des)cortesía. 3.1. Os estudos da (des)cortesía verbal: do enunciado ao discurso. 3.2. (Des)cortesía, habitus e rituais da identidade. 3.3. Comportamento educado, comportamento adecuado. 3.4. (Des)cortesía e estereotipos sociolingüísticos. 4. Imaxes, identidades e comportamento intercultural. 4.1. A identidade e a imaxe do punto de vista teórico. 4.2. A vulnerabilidade á imaxe e a súa relación cos discursos estereotipificadores. 4.3. Os malentendidos interculturais. 5. Conclusións. 6. Referencias bibliográficas. Anexo I

Como citar: Castro Lorenzo, L. (2020): “As voces da (des)cortesía en galego L2: aspectos sociodiscursivos", en Madrygal. Revista de Estudios Gallegos 23, pp. 121-137.

\section{Introdución}

As prácticas pedagóxicas viradas para os procesos de ensino e aprendizaxe de Linguas Estranxeiras (LE) e Linguas Segundas (L2) víronse afectadas nos últimos anos por directrices institucionais que impelen o profesorado a ensinar a lingua a partir dunha abordaxe

(...) orientada para a acção, na medida em que considera antes de tudo o utilizador e o aprendente de uma língua como actores sociais, que têm que cumprir tarefas (que não estão apenas relacionadas com a língua) em circunstâncias e ambientes determinados, num domínio de actuação específico. (Consello de Europa 2002: 29)

Como vemos, para o Marco Europeo de Referencia para as Linguas (MERL) (2002), o aprendente non é apenas falante, senón que é descrito como "actor social". As prácticas semióticas coas que se terá que familiarizar exceden o estritamente lingüístico: o estudante "ten que cumprir tarefas" e a lingua é útil, dalgún modo, para realización destas tarefas. $\mathrm{O}$ enfoque comunicativo que caracteriza o discurso institucional ligado á didáctica das linguas pon de relevo a importancia daqueles significados que se desprenden do contacto entre o interlocutor e as "circunstâncias", "ambientes" e "domínios de actuação" en que este se encontra localizado. Así, para abordarmos ás cuestións relativas a esta dimensión da comunicación en sintonía co prescrito no MERL (2002), será necesario partir da noción de comunidade de práctica, entendida como

(...) an aggregate of people who come together around mutual engagement in an endeavor. Ways of doing things, ways of talking, beliefs, values, power relations -in short, practicesemerge in the course of this mutual endeavor. As a social construct, a community of practice is different form the traditional community, primarly because it is defined simultaneously by its membership and by the practice in which that membership engages. (Eckert e McConnell-Ginet 1992: 464)

En canto actores engrenados nunhas prácticas, os usuarios da lingua móvense polo escenario social proxectando imaxes (é dicir, máscaras) deles propios nos demais. Esta idea constitúe un punto crítico para o ensino de linguas, especialmente de asumirmos, como fan Tracy (1990: 221) e Scollon e Scollon (200: 48), que non é posíbel a comunicación face-less. Na concepción de Brown e Levinson (1978/1987), a imaxe dos individuos é un fenómeno vulnerábel e transcultural (embora moldeado socioculturalmente) e a cortesía, a tecnoloxía social encamiñada a mantela a salvo. A operatividade da imaxe no curso das interaccións entre participantes permite explicar igualmente a existencia de máximas comunicativas que regulan o uso da cortesía (Leech 1983). O modelo de cortesía de Leech (1983) é, precisamente, o que mellor se axusta ao apuntado no MERL (2002):

As regras de delicadeza fornecem uma das razões mais importantes para um afastamento da simples aplicação do 'princípio de cooperação' (...). Elas variam de cultura para cultura e são uma causa frequente de mal-entendidos interétnicos, especialmente quando algumas expressões de delicadeza são interpretadas literalmente. (Consello de Europa 2002: 170)

Partíndomos das ideas expostas no MERL (2002), e tendo como obxectivo último o dunha mellor comprensión da realidade de dentro e fóra da aula, neste artigo exploramos, a partir da análise dun pequeno corpus de entrevistas, a ligazón que se establece entre os estudantes de galego L2, a lingua que estes aprenden e os 
fenómenos da imaxe e da (des)cortesía pragmática. Máis concretamente, procuramos dar resposta ás seguintes cuestións: como indexan os estudante de L2 os aspectos socionormativos ligados ás prácticas concibidas como corteses/ descorteses? Son conscientes da dependencia destas prácticas a respecto da comunidade de práctica ou asumen a existencia de regras universais? Son capaces de subtraerse á aplicación de xuízos de valor e categorizacións derivadas do contexto sociolóxico e identitario da súas comunidades de orixe? De que maneira incide a construción identitaria e da propia imaxe con relación á comunidade de acollida? Son os malentendidos interculturais un simple produto do descoñecemento das convencións pragmáticas e/ou sociolinguísticas ou existen igualmente factores extralingüisticos que condicionan o desencadeamento deste tipo de situacións?

Para a elaboración dos aspectos empíricos do traballo, demos voz a un grupo de alumnos de galego L2, todos eles adultos e procedentes de distintos países e rexións do planeta. Consideramos pertinente prestar atención a este perfil de "utilizador da lingua" para, en primeiro lugar, contribuír á construción dunha área da didáctica da lingua aínda non ben estudada no caso galego; e para, por outra parte, dilucidar se o discurso da (des)cortesía entra en resonancia cos discursos sobre a lingua galega irradiados polos grupos de poder. Aliás, afirmamos que a maneira en que aprende a lingua quen estuda unha lingua hexemónica (con capital-Estado) difire cualitativamente da maneira en que aprende a lingua un estudante dunha lingua minorizada (sen capital-Estado). Así, a tarefa do profesor de galego (ora sexa nun contexto de LE, ora de L2, ben como de L1) pasa por reconstruír as características sociopolíticas peculiares que os procesos de ensino e aprendizaxe da lingua (e das prácticas asociadas á súa utilización) adquiren no caso do territorio lingüístico galego.

\section{Consideracións previas}

As ideas que serán expostas ao longo das seguintes páxinas remiten a un traballo de investigación de dimensión maior realizado pola autora no marco do Traballo de Fin de Mestrado e que foi posíbel grazas á concretización das prácticas formativas contempladas no Mestrado Universitario de Profesorado de Educación Secundaria Obrigatoria e Bacharelato, Formación Profesional e Ensinanza de Idiomas, ofrecido pola Universidade de Santiago de Compostela. Estas prácticas desenvolvéronse na Escola Oficial de Idiomas da mesma cidade no mes abril de 2018. Durante ese período, reunimos un grupo de 6 estudantes da faixa etaria entre os 31 e os 49 anos, de distintas nacionalidades, con distinto tempo de estadía en Galiza e cuxa lingua inicial, excepto nun dos casos, non era o galego ${ }^{3}$. Todos eles eran, no momento da recollida dos datos, alumnos dun nivel intermedio, equivalente ao nivel B1 no MERL. Non obstante, é necesario aclarar que o grao de atención que se lle prestou na posterior análise a todas estas variantes macrodemográficas non se cinxe a unha interpretación cuantitativa clásica; hai que ter en conta que se trata dunha investigación cualitativa, por tanto, as posíbeis asociacións entre unha destas variantes sociais e un determinado trazo lingüístico ou comportamento comunicativo serán sempre de carácter hipotético.

No que concirne o método de recollida de datos, foron realizados, en primeiro lugar, un conxunto de tests pragmalingüísticos (de cuxa análise finalmente desistimos, por considerar que adoptamos unha perspectiva errada) e, por outra parte, varias entrevistas semidirixidas nas que se alentou os participantes, nun primeiro momento, a discorrer sobre a conduta comunicativa deles propios e dos individuos da súa área envolvente, tanto no seu contexto de orixe como na comunidade de recepción, procurando deste modo extraer índices de coñecemento tácito e reflexivo sobre o uso da lingua na súa dimensión interaccional. No momento da transcrición dos datos, proceso que foi efectuado co programa ELAN e tendo as convencións do Corpus Oral Informatizado da Lingua Galega (CORILGA) do Instituto da Lingua Galega como guía, contabamos con catro entrevistas individuais (I1, I2, I3 e I4) e unha entrevista grupal (en que participan I5 e I6), o que implica un volume total de $31 \mathrm{~min} 6 \mathrm{~s}$.

3 Todos estes datos poden ser consultados no Anexo I.

4 As convencións ortográficas do CORILGA sufriron, na práctica, pequenas alteracións encamiñadas a manter unha maior fidelidade aos aspectos interlingüísticos presentes na fala dos informantes; dado que, ao se tratar dun corpus con datos de aprendices de L2, consideramos importante manter intactos algunhas formas que se desvían do estándar oficial. Para o caso dI1, que responde a entrevista en español (a súa L1), a transcrición foi realizada recorrendo a un modelo de convencións ortográficas similares. 
Neste artigo, facemos apenas referencia a distintos fragmentos da comunicación obtidos das entrevistas con I1, con I3 e con I5 e I6. Nas análises inseridas na primeira parte do artigo $(3.2,3.3$ e 3.4$)$ abordaremos as reflexións metapragmáticas sobre o fenómeno da (des)cortesía que os informantes van desdobrando como resposta ás preguntas da entrevistadora (E). Neste tipo de interpretacións o papel que E desempeña na comunicación fica relegado para segundo plano: E é simplemente quen guía os puntos temáticos que se pretendía que os informantes tratasen. Con todo, as entrevistas poden ser concibidas como mostras de interaccións interculturais, dado que E participa no evento comunicativo cunha dupla función: alén do rol de guía, a súa presenza ten un valor simbólico importante na interacción, na medida en que as distintas identidades étnicas e nacionais que os informantes a ela asocian, ou para as que ela propia se orienta, funcionan como pivote á volta do cal poden ser eventualmente articulados distintos discursos persoais. Isto farase patente nos puntos 4.2 e 4.3 , nos que o ollar se dilata de modo a abranguer quer informacións metapragmáticas, quer tamén informacións pragmáticas: os entrevistados, para alén de responderen as preguntas da entrevistadora, estabelecen cos demais participantes vínculos interpersoais nos que se performan distintos tipos de identidades sociais, cuxos atributos son articulados en base a representacións da imaxe dun propio e do outro.

\section{As voces da (des)cortesía}

\subsection{Os estudos da (des)cortesía verbal: do enunciado ao discurso}

Sen dúbida, a obra que máis repercusión alcanzou no campo de estudo da cortesía pragmática é a lanzada por Brown e Levinson en 1978, e reeditada en 1987: Politeness: Some Universals in Language Usage. Estes autores defenden unha tese sobre a cortesía en que se equipara este fenómeno a un conxunto de estratexias comunicativas, designadas "atenuantes", que perseguen a finalidade de protexer a súa imaxe e a do interlocutor (Brown e Levinson 1978/1987). Así, cando falarmos de cortesía, estaremos a referirnos a unhas determinadas convencións lingüísticas e socioculturais vinculadas a contextos de uso específicos. Brown e Levinson (1978/1987: 61-65) delinean a súa análise do comportamento comunicativo en relación ao fenómeno da cortesía a partir dunha interpretación do concepto de "imaxe" de Goffman (1967) -noción á que retornaremos no punto 4.1-, na que esta pasa a ser bipartita (constará dunha dimensión positiva, asociada á necesidade de o falante ser aceptado como parte do grupo, e unha negativa, relacionada con valores como a liberdade e a independencia do individuo), e dotando o seu model speaker dunha certa capacidade de racionalización encamiñada a manter a harmonía interpersoal. Un axente deste tipo, a quen nos parecemos todos os membros adultos dunha sociedade (Brown e Levinson 1978/1987: 61), non procurará apenas respectar o principio de cooperación proposto por Grice (1975), mais tamén orientará as súas accións a manter a súa imaxe e a do(s) interlocutor(es) a salvo. Así, Brown e Levinson dirán do seu modelo que "the only essential presumption is what is at the heart of Grice's proposals, namely that there is a working assumption by conversationalists of the rational and efficient nature of talk" (978/1987: 4)

Estes autores defenden igualmente que nos intercambios comunicativos algúns actos de fala $^{5}$ (como as ordes, as suxestións, as burlas, as acusacións, a expresión de desacordo etc.) son "inherentemente ameazantes para a imaxe" (Brown e Levinson 1978/1987: 6568). Encóntrase entre os intereses do falante, segundo eles, o de contrarrestar esta ameaza; este interese deriva no desdobramento de estratexias de atenuación lingüística ${ }^{7}$, sendo que o maior ou menor grao de atenuación presente no enunciado que realiza o acto de fala estará determinado pola suma de tres variábeis situacionais: a distancia horizontal, a relación de poder existente entre os interlocutores e o custo de imposición da acción (Brown e Levinson 1978/1987:71-84). En contextos ideais, é suposto estes factores guiaren o emisor no momento de escoller un ou outro enunciado.

5 A aproximación á cortesía de Brown e Levincon 1978/1987 insírese na tradición dos actos de fala, liña de pensamento iniciada polo filósofo británico John Austin 1962.

6 Doravante, referirémonos a estas accións como "FTA(s)", abreviatura para o termo inglés Face Threating Act(s).

7 É preciso aclarar que na teoría da cortesía de Brown e Levinson 1978/1987 se dá un proceso de identificación entre atenuación e indirección lingüísticas. Véxase Escandell-Vidal 1996. 
A proposta de Brown e Levinson encaixa, en liñas xerais, coas propostas de Lakoff (1973) e de Leech (1983), igualmente inspiradas en Grice (1975). Lakoff (1973), coñecida por ser unha das primeiras lingüistas en estudar as relacións entre xénero e linguaxe, propuña tres principios básicos de cortesía: "non se impoña", "ofreza opcións" e "faga que o receptor se sinta ben". Por outra parte, Leech (1983) tratou de deseñar un marco teórico que explicase o principio da cortesía lingüística, tal como Brown e Levinson, propondo unha serie de máximas (de tacto, de xenerosidade, de aprobación, de modestia, de acordo e de simpatía) que os interlocutores procurarían respectar de modo a alcanzar un equilibrio na distancia social entre eles. Neste sentido, un acto sería máis cortés ou máis descortés dependendo do custo-beneficio que implicase para o destinatario.

Alén dos numerosos traballos nos que se lles dá continuación ás ideas de Brown e Levinson $(1978 / 1987)^{8}$, o modelo proposto por estes autores foi tamén amplamente criticado por autores que defenden unha aproximación de tipo discursivo ao fenómeno da cortesía (e da descortesía $)^{9}$. Non nos propomos desenvolver aquí por extenso o estado da cuestión no ámbito académico anglófono; con todo, queremos deixar constancia aquí da obxección feita por Mills (2003) -coa que concordamos plenamente- á premisa dun falante modelo que se caracteriza en Brown e Levinson (1978/1987) pola súa autonomía canto á tomada de decisións. Esta abstracción metodolóxica é refutada por Mills, quen dirá que "when speakers produce utterances, it is not just their conscious minds which construct utterances, but their unconscious motivations also play an important role" (2003: 18). As "motivacións inconscientes" das que fala a autora relaciónanse coas constricións contextuais (forzas filosóficas, políticas e económicas) que inciden no comportamento do individuo a través da súa subxectividade. Para explicar como a historia determina o falante, a través de distintos tipos de constricións, non só as do contexto inmediato da enunciación e o contexto situacional, mais tamén aquelas relacionadas coas (super) estruturas sociais que poden operar durante a interacción comunicativa entre as persoas,
Mills (2003: 35-36) servirase da noción de habitus (Bourdieu 1991).

Nas análises que veñen a continuación (3.2, 3.3, 3.4) afastámonos do modelo de Brown e Levinson (1978/1987) -sen por iso deixarmos de utilizar as súas ferramentas teóricas e metodolóxicas como "heuristic devices" (Mills 2015: 136)- en favor dunha maior adecuación ás aproximacións discursivas á (des)cortesía. Tomamos como principais referencias os traballos de Mills (2003, 2015), Watts et al. (1992), Locher e Watts (2005) e Watts (2005). Partimos da base de que a (des)cortesía está suxeita a variación intra e intercultural, social, situacional e individual. Así mesmo, considerámola un fenómeno dinámico, susceptíbel de ser negociado por parte tanto do emisor como do receptor, e configurado historicamente. Ao noso entender, a (des)cortesía remite a significados sociais inferíbeis a partir dun determinado enunciado nalgúns contextos, por causa de seren o resultado de procesos de gramaticalización; mais tamén a multiplicidade de discursos socionormativos que atinxen a conduta do(s) individuo(s) e do(s) grupo(s).

\section{2. (Des)cortesía, habitus e rituais da iden- tidade}

Mills (2003) introduce no seu marco teórico a noción de habitus tomándoa da socioloxía de Bourdieu, quen o refire como "the dispositions [which] generate practices, perceptions and attittudes which are «regular» without being consciously co-ordinated or governed by any «rule»" (1991: 12). Por outro lado, a mesma autora suxire estudar a (des)cortesía desprazando o foco do enunciado como unidade de análise e póndoo en fragmentos máis longos, o que segundo ela permitiría examinar o uso dos distintos axenciamentos comunicativos a nivel de discurso e metadiscurso (2003: 80-89). Tentemos aplicar isto no exemplo a seguir:

I6: pois é:: | casi parecido ao meu | o que pasa é que eu con a miña cultura orixinal $|<0.4>|$ a parte da:: | do respecto que temos entre::: | \{<dúbida> e:\} non por o: POSICIÓN sinó $\mid$ sobre todo por a idade $|<0.6>|$ os maiores temos muito:: $|<0.5>|$ muito respecto hacia o::s nosos maiores || entón con a xente | e

\footnotetext{
$8 \quad$ Algunhas das propostas continuadoras máis salientábeis son as de Fraser 1990, Kasper 1990 e Holmes 1995.

9 Véxanse as revisións críticas de Werkhofer 1992, Eelen 2001, Watts 2003 e Locher 2004.
} 
sobre todo | por exemplo nos casos $\mid$ profeso::res \||

I5: $\%\{<$ asentimento $>\operatorname{hum}\} \|$

I6: \%cando::: || \{<dúbida $>$ e:: $\}$ || A MAIORÍA $|<0.5>|$ pórtan+se:: son MUI respectables | pórtan + se ben $\mid$ son mui respectuosos ademais $\|$

I5: $\%\{<$ asentimento $>$ hum hum $\} \|$

I6: entó::n $|<1.3>|$ léva + se $|<0.9>|$ digamos | xa por naturalidade $\mid\{<$ dúbida $>$ e: $\}$ trata + los de distinta maneira | evidentemente $\|$ porque eles xa nos inspiran RESPECTO $\|$

I5: $[\{<$ asentimento $>$ hum hum $\}] \|$

I6: [inspiran] | ademais de confianza | RESPECTO $|<0.7>|$ e:: $\mid$ como a miña cultura tamén $|<0.6>|$ aos maiores independentemente a súa posición económica $\mid$ cultural ou profesional $\mid$ temos tamén respecto POR EXEMPLO $|<0.5>|\{<$ dúbida $>$ e:: $\}$ a:: aos maiores a todos $|<0.4>|$ tratamos $\mid$ de "vostede" $<0.7>$ | de "vostede" ||

I5: $\{<$ asentimento $>$ hum hum $\}$

I6: \%e de "don" ॥

E: $\{<$ asentimento $>$ hum hum $\} \|$

I6: SEXA QUEN SEXA $|<0.7>|\{<$ dúbida $>$ e:\} entón $\mid$ calquera actividade $\mid$ por exemplo de pequenos $|<0.7>|\{<$ dúbida $>$ e: e:: e:::\} $\mid$ ¿como se chama este:::? $|<0.7>|$ REVERENCIAMOS os maiores $|<1.3>|$ ENTÓN | claro ||

E: $\%\{<$ asentimento $>$ hum $\} \|$

Nesta ocasión, I6 está a dar resposta a unha das preguntas formuladas por $\mathrm{E}$, coa que se inquiría tanto a I5 como a I6 pola influencia das variábeis proposta por Brown e Levinson (1978/1987) no momento de realizar un FTA (poder, familiaridade e relevancia da acción comunicativa). Após a intervención de I5, I6 intervén pondo o foco no que el considera aspectos propios da súa "cultura orixinal". O discurso metapragmático de I6 remite tanto á dimensión lingüística da comunicación ("aos maiores, a todos, tratamos de "vostede" (...) e de "don"), como a elementos paralingüísticos ("de pequenos (...) reverenciamos os maiores"). O I6, ao relatar o comportamento dos membros da súa comunidade de orixe, remítenos a un determinado modo de organización social na que o grupo de xente máis vella exerce control sobre a xente de menor idade: "non por posición, sinó sobre todo por a idade (...) temos muito respecto hacia os nosos maiores". O habitus do que nos fala Bourdieu (1991) vese referido con clareza no seu relato: "lévase, digamos xa por naturalidade, tratalos de distinta maneira, evidentemente; porque eles xa nos inspiran respecto". As normas de comportamento cortés, herdadas historicamente e incorporadas como coñecemento subxectivo desde a infancia, responden, conforme se transloce nas palabras de I6, a unha vontade individual por manter a harmonía relacional nun determinado contexto. Con todo, como acabamos de ver, as formas de tratamento vinculados ao "respecto" poden ser a continuidade da dominación dun grupo social sobre outro ('a xente de maior idade sobre a xente de menor idade'): o poder que os máis vellos exercen sobre o resto da comunidade, en forma de autoridade, tradúcese nunhas constricións contextuais moi concretas, ás cales, nalgunhas ocasións, poderemos acceder a través da conduta verbal e non-verbal dos participantes.

Inmediatamente a continuación, I6 pasa a describir un evento comunicativo moi concreto e fortemente ritualizado, no que, de novo, se dá unha correspondencia directa entre as formas de comportamento adecuadas ao contexto e o que o individuo considera educado:

I5: ¿a túa nai e a teu pai tamén? ॥

I6: na\# | non | [a:::] nos\# ||

I5: [tamén] ॥

I6: a noso pai e a nosa nai NO tanto | pero por exemplo eu na orix\# $\mid\{<$ dúbida $>$ e:: e:\} unha reunión $|<0.5>|\{<$ dúbida $>$ e: $\}$ familiar ou tal | unha:: comidiña $\|\{<$ dúbida $>$ e:: $\}|<0.4>|$ cando:: | antes de xantar ||

I5: $\{(\mathrm{P})<$ asentimento $>$ hum hum $\} \|$

I6: pedim\# | despois de estar servidos na mesa | está\# de xantar | pedimos permiso || para empezar a xantar $|<0.5>|$ pero ADEMAIS despois de xantar $\|$ e de decir $|<0.5>|\{<d u ́-$ bida $>$ e: $\}$ "muitas grazas" || porque nós decimos despois de xantar | TODOS decimos "muitas grazas" | [A TODOS] ||

E:

$[\{<$ asentimento $>$ hum $\}] \|$

I6: (INH) | e aos maiores | e sobre todo ao máis maior $|<0.8>|$ da:: $\mid$ que un ve que está na sala | un va $\mid$ pára + se e va $\mid$ a reverenciar $\mid$ dá + lhe a cabeza \|

$\mathrm{E}:\{(\mathrm{PP})$ guau $\} \|$

I6: e o maior ten que poñer+lle a man a un $<0.6>\mid\{(\mathrm{F})$ como dicendo $\}||$

I5: $\quad[\{<$ asentimento $>$ hum hum $\}] \|$ 
I6: “[eres res]pectuoso" | “eres educado" ||

$\mathrm{E}:[\{<$ asentimento $>$ hum $\}] \|$

I6: $\quad$ [OU SEXA] $\mid\{<$ dúbida $>$ e: $\}$ ¿como se di? $\{<$ dúbida $>$ e: $\}|<0.6>|<$ chascado $>$ $|<0.5>|\{<$ dúbida $>$ e: $\}||\{<$ dúbida $>$ e: $\}$ | $\{<$ cansazo $>$ ai $\}$ || CERTIFICANDO | calificando que TI \|

$\mathrm{E}:[\{<$ asentimento $>$ hum $\}] \|$

I6: [estás sendo] ॥

I6: MANTENDO | o respecto ||

I5: [entendo] $\|$

E: [claro] ॥

O intercambio comunicativo que ten lugar entre a persoa "máis maior que un ve que está na sala" e o resto de convidados á reunión familiar está engrenado nunha actividade social moi concreta (o "xantar"); alén diso, quen participa no evento comparte, neste caso de maneira moi acentuada, unha serie de expectativas comúns, modeladas culturalmente, e unha serie de asuncións a respecto do "information state within which the strip of interaction is developed" (Watts et al. 1992/2005: 51). Este background sociocultural, que parece verse intensificado en comunidades de práctica máis tradicionais, repercute na comunicación de modo que, para quen nela participa, resulta moi fácil inferir os significados que se desprenden dos movementos corporais ("dar a cabeza" > "reverenciar"). Os significados implícitos, de carácter interpersoal, remiten a uns roles comunicativos determinados, aos cales podemos acceder, quer a partir da observación desas prácticas, quer acudindo -como é o caso- ao discurso metapragmático articulado á volta dese evento comunicativo, no que o informante explicita a través de etiquetas lingüísticas parte deste coñecemento intersubxectivo. Así, I6 fala de "reverenciar" e "dar a cabeza", ambas as accións simbólicas que perseguen unha finalidade de que o máis maior "lle poña a man". Deste xesto non-verbal desprenderase o significado "eres respectuoso, eres educado". Para conseguir a súa "calificación" de bos modos e, en consecuencia, a "certificación" de membro adecuado do grupo, o individuo non depende de fórmulas verbais de ningún tipo:
Rituals are the limiting case of situations of imposition in which, through the exercise of technical competence which may be very imperfect, a social competence is exercise - namely, that of the legitimate speaker, authorized to speak with authority. (Bourdieu 1991:41)

\subsection{Comportamento educado, comportamen- to adecuado}

A idea do habitus está presente tamén na aproximación ao discurso da (des)cortesía que fan Watts et al. (1992), Locher e Watts (2005) e Watts (2005). Para este autores, o conxunto de hábitos comunicativos que un falante, de modo máis ou menos inconsciente, fixa como normas configuran o politic behaviour, concepto co que establece unha categoría máis abranguinte que a do polite behaviour (Watts et al. 1992; Locher e Watts 2005; Watts 2005). O comportamento adecuado do individuo é aquel encamiñado a manter unha orde ou equilibrio na relación cos demais individuos do grupo a que pertence, mentres que o comportamento educado (sendo que se trata igual e necesariamente dun acto de carácter relacional) é o resultado da valoración que recae dun membro dunha comunidade sobre outro (o cal, entendemos, pode pertencer a esa mesma comunidade ou non). Estes dous aspectos nin sempre se solapan: "a great deal of the relational work carried out will be of an unmarked nature and will go largely unnoticed" (Locher e Watts, 2005:11); e, precisamente, por causa de non ter sido obxecto de ningunha valoración, entrará na categoría de "comportamento adecuado". A gráfica representada na Figura 1 sintetiza tales ideas (cf. infra).

De un intercambio comunicativo activar as expectativas do(s) interlocutor(es) a respecto do comportamento do outro, pode acontecer que este sexa xulgado quer positivamente ("educado") e, en consecuencia, "adecuado"; quer negativamente ("maleducado" / "educado de máis"), e por tanto, "non adecuado". Nótese que Locher e Watts (2005) acrecentan unha outra categoría á orde da (des)cortesía: a da conduta over-polite ("educado de máis"). A pesar de este concepto non ser operativo no noso corpus, intuímos que se trata dunha ferramenta moi útil para a interpretación dunha

10 Ao longo do traballo, referirémonos ao binomio politic behaviour / polite behaviour como "comportamento adecuado" / "comportamento educado", ou mesmo aos seus respectivos antónimos "inadecuado / maleducado". Consideramos que unha tradución así se cinxe bastante ben ao sentido do orixinal. 


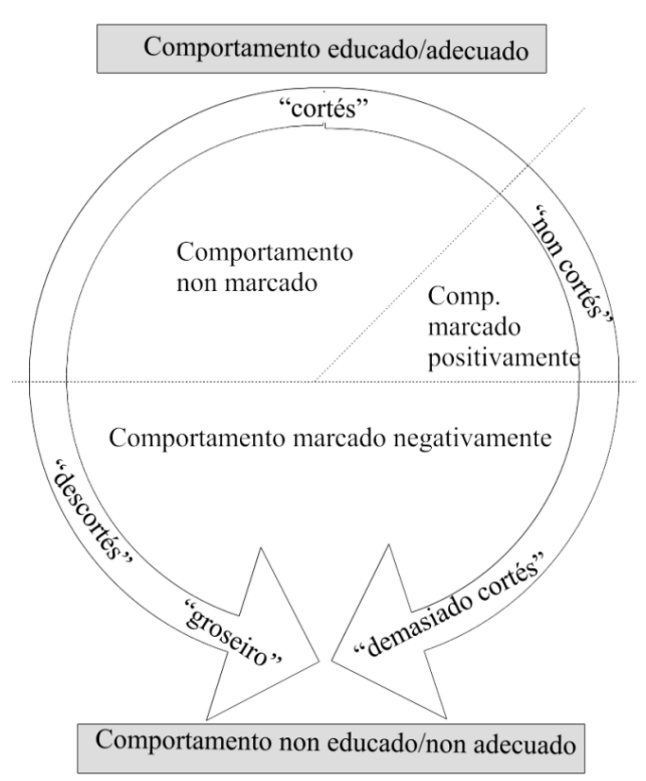

Figura 1: Gráfica do traballo relacional. Baseada en Watts (1992/2005: xliii)

gran parte dos (des)encontros interculturais $\mathrm{Na}$ análise do Exemplo 1, detectouse unha correlación entre a conduta cortés dos individuos e o mantemento dunha determinada orde social, e con ela, a reprodución duns determinados valores en detrimento doutros. Isto tórnase de novo evidente na seguinte mostra:

E: $\{<$ lendo $>$ " ¿cres que as variantes poder familiaridade e relavancia da petición" $\}$ | é dicir | "canto de esperable E" | \{<lendo> "inflúen en ti á hora de decantar+te por unha maneira de falar ou outra?"\} ||

E: ¿como? | $\{(\mathrm{P})$ ¿como in[flúen?] $\} \mid$

I1:

[s::í] | sí| influyen

a ver | en cuanto a:: la familiarida::d | pues | con un familiar y una amistad uno se sien\# | $\{(\mathrm{AC})$ dependiendo de la amistad también $\}$ | si es muy cercana $\mid$ uno $\mid$ se siente más cómodo ¿no? al: | y a lo mejor pues | cuestiones como: | "por favo::r" | a ver no tienes tanta:: | TANTO CUIDADO ¿no? | a la hora de: de de preguntar algo o:: $|<0.5>|$ o pedir algo $|<0.8>|\{<$ dúbida $>$ e::: $\} \mid$ también pasa con las personas pues que tienen el poder ¿no? con\# | bueno el caso $\{<$ incerto $>$ pasaba $\}$ la:: | 1\# | la profeso:ra $|<0.4>|\{<$ dúbida $>$ e:::: que sé yo | TU JE:FE\%

E: $\{<$ asentimento $>$ hum $\} \%$

I1: no es lo mismo que se hablaras cue\# | con un amigo: $\mid$ o: $|<0.6>|$ pero:: $\mid$ bueno $\mid$ en mi caso por ejemplo: | una persona que me atiende en el caso de un restaurante $\mid$ también tiene:: | es una persona que me está prestando un servicio por lo tanto requiere un:: $|<0.6>|$ un respeto $\mid$ ¿no? ||

No Exemplo 3, I1 reflexiona a propósito dos distintos factores que entran en xogo cando realiza unha acción por medio dunha variedade lingüística concreta. Nun primeiro momento, admite como determinantes dous aspectos mencionados con anterioridade por $\mathrm{E}$, que coinciden cos que Brown e Levinson (1978/1987) propoñen no seu modelo: a frecuencia das interaccións entre os interlocutores (“(...) con un familiar y una amistad (...) uno se siente más cómodo) e a distancia vertical entre eles ("También pasa con las personas pues que tienen el poder (...)). O factor "amizade" é seccionado en dúas categoría nas cales o criterio diferenciador é a intimidade: "dependiendo de la amistad también. Si es muy cercana..."). Canto á pertinencia do "poder vertical", I1 ilústrao pondo como exemplo dúas persoas con roles asociados tradicionalmente á figura da autoridade ("la profesora" e "tu jefe" son personaxes cos que a informante entrará en contacto previamente durante a realización dos tests pragmalingüísticos). A seguir, aparece o marcador discursivo "pero", que nega parcialmente algunha das afirmacións anteriores e que provoca no relato unha virada retórica. $\mathrm{O}$ punto de partida argumental é que o poder do interlocutor é un elemento chave no momento de desdobrar estratexias de atenuación ("cuestiones como "por favor" (...) no es lo mismo que si hablaras con un amigo"), porén isto é parcialmente refutado nun inciso posterior: "en mi caso por ejemplo, una persona que me atiende en el caso de un restaurante (...) es una persona que me está prestando un servicio por lo tanto requiere un (...) respeto"). A I6 colócase a si propia nunha determinada posición discursiva e, partindo deste marco de acción, exerce resistencia ao discurso da (des)cortesía proposto pola investigadora. O discurso de I1 acerca da (des)cortesía é un discurso igualitarista que tende ao rexeitamento das xerarquías de poder tradicionais. En paralelo co que acontecía nos exemplos 1 e 2, a (des)cortesía serve a indexar os dereitos e obrigas sociais que os falantes reclaman para si propios e para os seus interlocutores; isto é, para I1 o adecuado ideoloxicamente no contexto descrito é ter unhas formas educadas ("merece un respecto"). 


\section{4. (Des)cortesía e estereotipos sociolingüís- ticos}

Mills (2003: 184-190), ao explorar a correlación entre o uso dunhas determinadas variedades lingüísticas e a consecución duns parámetros de adecuación social, sinala como fundamental neste tipo de análises a noción de "estereotipo". Apoiándose no concepto do habitus bourdieuano (Bourdieu 1991), esta autora afirma que o estereotipo, podendo constituír a representación mental dun escenario eventualmente axustado á realidade dun grupo de individuos, "is one noticeable form of behaviour which is afforded prototypical status, backgrounding all of the other more common (...) forms of behaviour" (Mills 2003: 184). Nese sentido, o estereotipo forma parte da normalidade (discursiva) máis do que da anormalidade; e isto adquire sentido se partimos, como fai Mills (2003: 184), da idea de que algunha versión do estereotipo é (re)producida en esferas que median na nosa experiencia común en canto membros dunha audiencia. Observemos o exemplo a seguir:

E: $\{<$ lendo $>$ "¿recordas algún malentendido cun galegofalante por che resultar ESTE de\# demasiado descortés" $\}|<0.7>|\{<$ len$d o>$ "OU por pensar EL que ti foras descortés?"\} ||

I3: $\{<$ dúbida $>$ e: $\}$ eu penso que non soy descorté::s | [\{(risas) moi] tas veces $\}||$

E: $[($ risas $)] \|$

E: $\{<$ asentimento $>$ hum hum $\} \mid$

I3: porque:: | procuro ser educado cando pido as cousas \|

E: $\{<$ asentimento $>$ hum hum $\} \|$

I3: pero $\|$

E: ¿[pero] por diferenzas culturais | ou así? ||

I3: $[\mathrm{s} \#] \|$

I3: $\{<$ dúbida $>$ e:: $\}$ s s:::i que:: $|<0.4>|$ s\# | na zon\# | bueno na zona rural o::: fóra das cidades $\mid \mathrm{s} \#\{<$ dúbida $>$ e:: $\}$ nóta + se:: $|<0.4>|$ o discurso moito más\# | máis directo e máis bruto [da::] \|

E:

$[\{<$ asentimento $>$ hum $\}] \|$

I3: da xente de aquí para pedir as cosas | se:n | sen respecto $\|$

Perante a insistencia da entrevistadora, que pregunta a I3 se se lembra dalgún malentendido cun galegofalante, este deseña un contexto comunicativo en que se serve de dous grupos, a comunidade galega urbana fronte á comunidade galega rural ("na zona do rural $o$ fóra das cidades"), e en que lle atribúe ao segundo características comportamentais negativas: "nótase o discurso moito máis directo e máis bruto da xente de aquí para pedir as cousas. Sen respecto". Neste caso, o discurso do informante axústase ao teorizado por Brown e Levinson (1978/1987), na medida en que reproduce un certo isomorfismo entre indirección lingüística e cortesía; en consecuencia, o "directo", na súa intervención, fica asociado ao "bruto", ao propio "da xente de aquí", cuxo comportamento verbal para unha determinada acción comunicativa ("para pedir as cousas") é definido en relación ao impacto que isto produce no receptor ("sen respecto").

Non coñecemos os feitos que subxacen ao discurso metapragmático dI3; entre outras razóns, porque este non proporciona datos ou exemplos concretos que xustifiquen a súa afirmación en ningún momento da entrevista. Igualmente, non é posíbel esclarecer se este posicionamento discursivo é o resultado de interaccións pasadas en que o informante e a xente galega de "fóra das cidades" actuaron norteados por principios (quer pragmalingüísticos, quer sociopragmáticos) diferentes e determinados culturalmente. Con todo, resulta evidente que a xeneralización feita polI3 canto ao comportamento comunicativo da xente do rural funciona nun discurso ideolóxico articulado á volta da estigmatización de certos grupos de falantes.

Álvarez Cáccamo (2000), ao reflexionar sobre o peso dos medios de masas (CRTVG) na variación sociolingüística da comunidade galega, sinala que estas institucións (re)producen un esquema ideolóxico en que, embora ser o galego a lingua de uso habitual (fronte ao que acontece na maior parte dos medios hexemónicos do territorio), esta é seccionada en dúas variedades: "por lo general, el AltoGallego se identifica con una variedad regularizada del gallego-portugués de Galiza (el "gallego común"), mientras que dentro del BajoGallego se encuentra lo dialectal, lo irregular y lo coloquial" (2000: 7). O AltoGalego posúe unha maior semellanza estrutural co español; non por acaso, o AltoGalego é das dúas a variedade "neutra" (Álvarez Cáccamo 2000). Por súa vez, nos medios públicos da Galiza, o BaixoGalego, caracterizado por unha fonética tradicional con seseo e gheada, e cunha prosodia menos interferida, indexa uns determinados grupos de falantes (as clases populares rurais), 
e deste xeito contribúese para a subordinación dos seus membros (Álvarez Cáccamo 2000). Non se trata, por tanto, dunha dicotomía inocua e/ou baseada nun criterio científico, senón que o que interesa é establecer un "contraste estratégico entre el BajoGallego y el AltoGallego como códigos comunicativos interpretativos y re-productores de las identidades de clase" (2000: 7).

Sostemos que nas palabras de I3 pode estar a operar este conxunto de ideas, sendo que o proceso de diferenciación entre as identidades e as imaxes sociais implicadas na entrevista entenderíase como a continuidade dunha orde sociolingüística promovida no(s) discurso(s) mediático(s) e comprensíbel do punto de vista das posicións de clase. Este proceso conduce, no decorrer da entrevista, ao establecemento do seguinte esquema de identificacións: a 'xente de aquí do rural, directa, bruta e sen respecto' fronte á 'xente de aquí das cidades', que non mostra tales características; ' $e u$ fronte á xente de aquí', mais non fronte 'á xente de aquí das cidades', apenas 'fronte á xente de aquí do rural' (por tanto, 'eu non-directo, non-bruto, con respecto'). O I3, que leva soamente tres anos instalado na Galiza, non se define a si propio como galego; alén diso, non contamos con datos biográficos suficientes para certificar que o informante estivo en contacto coas representacións que referimos. Todo isto podería inclinarnos a pensar que I3 non recibiu a influencia, directa e/ou indirecta, dos discursos sinalados na análise; e de ser así, este feito anularía a validez das correspondencias que argumentamos. Non obstante, queremos pensar (e en certa medida presupomos isto ao longo de todo o artigo) que os informantes si que_se encontran inmersos en contextos, dentro e fóra da aula, en que estas convencións sociolingüísticas están presentes en forma de inputs que os estudantes reciben e, nalgunhas ocasións, reteñen. Alén desta cuestión, e para o caso concreto de I3, vasco, cabe mencionar outra idea: a de que o AltoGalego e o BaixoGalego reproducen, ao noso entender, esquemas ideolóxicos predominantes no ámbito do Reino de España.

\section{Imaxes, identidades e comportamento in- tercultural}

\subsection{A identidade e a imaxe do punto de vista teórico}

A nosa concepción da imaxe cínxese no fundamental á clásica definición proposta por Goffman (1967):
The term face may be defined as the positive social value a person effectively claims for himself by the line others assume he has taken during a particular contact. Face is an image of self delineated in terms of approved social attributes - albeit an image that others may share, as when a person makes a good showing for his profession os religion by making a good showing for himself. (1967: 5)

Non obstante, nas análises dos puntos 4.2 e 4.3 este concepto será posto en relación co fenómeno da identidade. Apoiámonos en Locher (2008), quen subliña a necesidade de estudar a (des)cortesía dunha perspectiva construtivista, en que a imaxe, ao igual do que as demais identidades do individuo, pasa de ser un elemento preexistente á interacción a definirse como produto das negociacións entre falantes. Ben como en Goffman (1967) e nos seus seguidores o axente inviste esforzos en perfilar a imaxe del propio e dos seus interlocutores (chamarán a isto facework), nas teorías posmodernas da identidade esta é concibida como o resultado de prácticas discursivas locais (aquelas que constitúen o identitywork). Locher (2008) destaca o paralelismo destes dous cadros interpretativos e postula a existencia dunha categoría máis abranguinte, vinculada aos aspectos interpersoais da comunicación, que englobaría face e identitywork: o relational work (Figura 1). Con este termo referirá "the way in which the construction of identity is achieved in interaction, while identity refers to the "product" of these linguistics and non-linguistics processes" (Locher, 2008:511). Para entendermos as distintas realidades que subxacen a estes procesos, Locher (2008) propón acudirmos á teoría das identidades de $\mathrm{Bu}-$ choltz e Hall (2005), á vez que nos dá algunhas indicacións útiles para aplicar as ferramentas teóricas e metodolóxicas propostas por estas autoras.

Bucholtz e Hall (2005:586) definen a identidade como "the social positioning of self and other" e postulan cinco principios a través dos que é posíbel estudar a construción das identidades no seo da interacción do punto de vista sociocultural e discursivo:

- O principio de emerxencia: a identidade é case sempre o produto da interacción comunicativa, e non un fenómeno preexistente a ela.

- O principio de posicionalidade: a identidade, ao se tratar dun fenómeno que emerxe a través dunhas prácticas lingüísticas, ten 
carácter local, a pesar de poder estar determinada por categorías macrodemográficas (xénero, cultura, idade etc.).

- O principio de indexicalidade: os individuos oriéntanse cara a categorías identitarias mediante mecanismos lingüísticos como as etiquetas, explícitas ou non, as implicaturas e as presuposicións, as actitudes, os estilos, as estruturas e os sistemas lingüísticos.

- O principio de relacionalidade: a identidade é un fenómeno relacional; isto é, constrúese na(s) relación(s) que o individuo establece cos demais. Así, a identidade non é producida de forma autónoma, mais en relación a outras posicións identitarias e a outros actores sociais. Estas relacións complementarias poden ser articuladas aténdose a tres binomios: o da "adecuación" / "distinción" (neste caso, o actor colocará a énfase no grao de similitude ou diferenza entre un e outro atributo); o da "autenticación" / "desnaturalización" (algúns usuarios da lingua serán etiquetados como xenuínos nunha determinada actividade, fronte a outros cuxa característica será o "artificio"); e, finalmente, o da "autorización" / "ilexitamación", o cal remite ao grao de continuidade discursiva con determinados poderes e ideoloxías institucionalizadas.

- O principio de parcialidade: a identidade non é necesariamente unha categoría consciente, e neste sentido pode emerxer no curso da interacción de modo máis ou menos intencional.

\subsection{A vulnerabilidade á imaxe e a súa rela- ción cos discursos estereotipificadores}

A idea de que a imaxe que reclamamos para nós propios e para os demais é un fenómeno emocionalmente vulnerábel encóntrase xa presente en Goffman (1967), e é recorrente nos estudos de (des)cortesía desde Brown e Levinson (1967/1987). Estes últimos colocan as participacións emocionais entre as forzas que inclinan os falantes a procurar manter a súa imaxe e a do interlocutor a salvo (Brown e Levinson 1967/1978: 61). Tentemos agora esclarecer a relación que se establece entre este fenómeno, as dinámicas de negociación da imaxe e a introdución de estereotipos no transcurso da interacción. Partimos do Exemplo 6, fragmento en que se reproduce de forma ampliada o xa visto no Exemplo $4^{11}$ :

(6)

E: $\{<l e n d o>$ "¿recordas algún malentendido cun galegofalante por che resultar ESTE de\# demasiado descortés" $\}|<0.7>|\{<$ len$d o>$ "OU por pensar EL que ti foras descortés?"\} ॥

I3: $\{<$ dúbida $>$ e: $\}$ eu penso que non soy descorté::s | [\{(risas) moi] tas veces $\} \|$

E:

$[($ risas $)] \|$

E: $\{<$ asentimento $>$ hum hum $\}$

I3: \%porque:: | procuro ser educado cando pido as cousas $\|$

E: $\{<$ asentimento $>$ hum hum $\} \|$

I3: pero $\|$

E: i[pero] por diferenzas culturais | ou así? ||

I3: [s\#] ॥|

I3: $\{<$ dúbida $>$ e:: $\} \mid$ s:::i que:: $|<0.4>|$ s\# | na zon\# | bueno na zona rural o::: fóra das cidades $\mid$ s\# $\{<$ dúbida $>$ e:: $\}$ nóta + se::: $|<0.4>|$ o discurso moito más\# | máis directo e máis bruto [da::] \||

E:

$[\{<$ asentimento $>$ hum $\}] \|$

I3 :da xente de aquí para pedir as cosas $\mid$ se:n $\mid$ sen respecto $\|$

E: $\{<$ asentimento $>$ hum $\} \|$

E: vale $\|$

I3: moi brusco \|

E: ¿moi brusco? | ¿esa é a túa impresión? | ben ben $\|$

Cando se lle pregunta a I3 por posíbeis malentendidos acontecidos en situacións de contacto con membros da comunidade galega, I3 indexa, a través de etiquetas explícitas, unha determinada imaxe social coa que se identifica: "no soy descortés", "procuro ser educado". Esta imaxe, que o informante reclama para si propio, vese reforzada cando, posteriormente, constrúe a alteridade (neste caso, unha alteridade colectiva, que el identifica coa 'xente galega do rural") mediante as categorías "máis directo", "máis bruto", "sen respecto". I3 asocia o comportamento educado a un discurso da deferencia, e este esquema de expectativas

11 Véxase a sección 3.3. 
emerxe de novo ao se activar na entrevista o "principio de relacionalidade" (Bucholtz e Hall 2005): o falante colócase a si propio na posición de 'falante deferente' (e, por tanto, 'politicamente adecuado'), que se opón aos roles do grupo que describe ('falantes non-deferentes', 'politicamente non-adecuados'). Trátase dun proceso de relacionamento por "distinción", fenómeno bastante común no que atinxe a negociación das identidades na interacción, dado que "language is an especially potent resource for producing it [the relation of distinction] in a variety of ways" (2005: 600).

Unha vez introducido o estereotipo sociolingüístico ("na zona rural o fóra das cidades (...) nótase o discurso moito (...) máis directo $\mathrm{e}$ máis bruto da xente de aquí para pedir as cosas; (...) sen respecto. (...) Moi brusco."), a entrevistadora envólvese no intercambio comunicativo (re)activamente. Estamos a movernos agora do nivel metapragmático para o pragmático: quen á partida apenas se serve das quendas de palabra para ofrecer movementos de apoio conversacionais (os asentimentos, o "vale") e para obter anécdotas e relatos autobiográficos dI3 ("pero por diferenzas culturais ou así?"), reaxe perante o discurso do interlocutor con preguntas directas ("Moi bruscos?" "Esa é a túa impresión?") e mediante xuízos redundantes ("Ben, ben"). Ocórrensenos dúas posíbeis interpretacións, en termos de intencionalidade, para explicar o que subxace ao comportamento comunicativo da entrevistadora: a) con "Ben, ben", E está a realizar un acto de fala directo, en que o significado proposicional é o que E pretende que o interlocutor infira como válido, sendo que, de ser correcta esta hipótese, E estaría a performar unha estratexia de cortesía positiva (Brown e Levinson 1978/1987), e b) o significado proposicional de "Ben, ben" non é o único que E quere que o seu interlocutor infira como válido porque, de feito, non está a tentar ser cooperativa, polo menos non completamente, co que di. Consideramos que esta segunda análise é máis plausíbel e apoiámonos na noción de "cortesía sarcástica ou finxida", unha das cinco estratexias de descortesía coas que, segundo Culpeper (1996: 355-357) é posíbel realizar un FTA. O característico da cortesía sarcástica é que nela opera o "principio de ironía" proposto por Leech (1983): "If you must cause offence, at least do so in a way which doesn't overtly conflict with the PP [Politeness Principle], but allows the hearer to arrive at the offensive point of your remark indirectly, by way of an implicature" (Leech 1983: 82).

De asumirmos esta explicación como válida, teremos igualmente que asumir que E está a activar a posibilidade de que I3 interprete que a súa imaxe foi, ou polo menos puido ser, ameazada de parte de E. Chegadas a este punto, é cando se torna pertinente falar de vulnerabilidade á imaxe: a conduta verbal de $\mathrm{E}$ non parece indiferente á imaxe que I3 proxecta sobre a comunidade galega, e isto explica a aparición da cortesía sarcástica, cuxa función última, neste caso, sería a de conseguir unha mudanza na actitude de I3 face ao grupo referido, co que $\mathrm{E}$ se identifica en maior ou menor medida. Como se viu na análise do Exemplo 4, os estereotipos poden constituír visións reducionistas e interesadas das características dun determinado sector da sociedade. Esta é a idea que parece operar no discurso de E cando (re)constrúe as palabras de I3 outorgándolles novos significados. En termos de traballo relacional, a intervención de I3 non se encontra entre as expectativas que E coloca sobre o seu interlocutor/informante. Dito doutro modo: o comportamento de I3 non pasa desapercibido para $\mathrm{E}$, dado que (baseándonos na súa reacción) para ela este comportamento está marcado negativamente por causa de chocar de fronte co que E considera adecuado ideoloxicamente.

\subsection{Os malentendidos interculturais}

Pode surgir um problema, quando um campo conceptual específico está organizado em L1 de modo diferente de L2, o que é, aliás, frequente, sendo a correspondência entre palavras parcial ou inexistente. Até onde vai essa falta de correspondência? A que mal-entendidos pode ela conduzir? Considerando este facto, que prioridade deve ser dada a estas questões num determinado estádio de aprendizagem? A que nível deverá ser exigido ou considerado o domínio da distinção? Poderá deixar-se que o problema acabe por se resolver por si mesmo com a experiência? (Consello de Europa 2002:186-187)

No Exemplo 6 viuse como, na comunicación intercultural, os estereotipos sociolingüísticos, polo menos de emerxeren asociados a atributos negativos, son susceptíbeis de constituír FTAs cando algún dos interlocutores se identifica coa(s) imaxe(s) atinxida. Non temos a certeza de que neste tipo de situacións sexa posíbel falar de "malentedidos". Porén, no corpus existen datos que apuntan a que a falta de "correspondência" sinalada no MERL (2002) crea 
contextos de incompresión susceptíbeis de abordar na aula de linguas dunha maneira bastante simple, so unha óptica pragmalingüística:

E: $\{<$ lendo $>$ "¿que pensas da forma en que piden cousas os galegos e as galegas?" $\}$ $<0.4>\mid\{<$ lendo $>$ "¿notas algunhas diferenza entre:: a comunidade galega e:" $\} \mid\{<$ len$d o>$ "e a de túa orixe" $\}$ nese sentido? $\mid<0.4>$ | \{<lendo $>$ "e a túa de orixe" $\mid$ perdón ||

I1: (INH) | sí | a ver yo: | \{(AC) no sé si es que estoy loca pero:\} | yo siento que:: piden las cosas como que si fuese una obligación que uno se las tuviera que dar $|<0.5>|$ ¿no? $\|$

$\mathrm{E}:\{<$ asentimento $>$ hum hum $\} \|$

I1: $\{<$ dúbida $>$ e:::: $\}$ PERO depende | porque:: si los gall\# | si un gallego le pide a un gallego $\{(\mathrm{DC})$ ya cambia la historia $\}$ ¿no? $|<0.4>|$ es como preguntándo+le si lo $\{(\mathrm{DC})$ tiene $\} \|$

I1: $\quad[\{<$ dúbida $>$ e:: $\}] \|$

E: $[\{<$ asentimento $>$ hum $\}] \|$

I1: “¿te\# | ¿tendrás un:::” ||

E: $\{<$ asentimento $>$ hum hum $\} \|$

I1: $\{<$ dúbida $>$ e: $\}$ entonces ya es como::: $1 \#$ | forma | amable ||

E: [claro] \|

I1: [pero] hay que entender+lo | claro \|

No Exemplo 7, I1, incitada por E, introduce unha xeneralización que ben podería resultar nunha ameaza para a imaxe de E ("piden las cosas como que si fuese una obligación que uno se las tuviera que dar"). Porén, a diferenza do que acontecía no Exemplo 6, a informante sérvese neste caso de estratexias atenuantes que envolven o acto de fala, de cuxa problemática I1 parece ser consciente: con anterioridade dirá "no sé si es que estoy loca, pero yo siento que" e terminará cun "¿no?”. Perante isto, $\mathrm{E}$ asinte cooperativamente. A continuación, e vamos agora ao punto que aquí interesa, I1 amplía a información relativa á súa reflexión metapragmática: "pero depende, porque (...) si un gallego le pide a un gallego ya cambia la historia (...) Es como preguntándole si lo tiene: (...) "tendrás un...?". Entonces ya es como (...) la forma amable". I1 expón dúas interpretacións para o enunciado "tendrás un [o que for]?", sendo esta a fórmula lingüística utilizada para realizar o acto de fala directivo ("si un gallego le pide a un gallego"): á partida, I1 enfoca no contido literal/semántico da expresión ("es como preguntándole si lo tiene"), para a continuación colocar unha explicación en que incorpora o significado pragmático ("es como la forma amable"). Comprender as connotacións sociais do enunciado "tendrás un [o que for]" require dun certo grao de competencia pragmalingüística: "pero hay que entenderlo, claro". A idea que nos traslada I1 axústase a unhas das teses defendida por Fernández López (2007-2008): "El futuro que Koike (1989) señala como el menos cortés de los tiempos de indicativo para el portugués de Brasil parece en gallego codificar mayor deferencia que el presente, sobre todo la forma negativa en estructuras interrogativas" (Fernández López 2007-2008: 99).

Inmediatamente, I1 pasa a darnos máis información relativa ao que ela percibe como diferenzas interculturais: E:
$\{$ no[tas] $\|$ si $\mid$ segue\# | claro | vale $\}$ | ¿pero si que

I1: [tam]bién cambian muchas\# \|

I1: $\{<$ dúbida $>$ m: $\} \mid$ que si hablas en castella\# | si\# s\# saben que no eres gallega $\mid<0.4>$ | ya::: | es: $\mid<$ chascado $>$ | existe una cierta desconfianza $\|$

E: $\{<$ asentimento $>$ hum hum $\} \|$

I1: que no por eso te:: tratan mal ni mucho menos pero:: | Sí NO ES LO MISMO ||

I1: [no es lo mismo] ॥

E: [entendo] $\|$

I1: sí \|

I1 afirma que "también cambian muchas [cosas]", entre elas que "si (...) saben que no eres gallega -I1 estala a lingua- existe una cierta desconfianza". O elemento paralingüístico (chascado) ofrece moita información pragmática: como se se tratase do seu detonante, o estalido coa lingua constrúe como ameazante o acto de fala que I1 emite a continuación ("existe una cierta desconfianza"). Se quixermos traducilo a unha linguaxe verbal, teríamos algo do tipo 'sei que o que vou dicir é un FTA para ambas, mais preciso de dicilo'. I1 atenúa a acusación máis adiante ("que no por eso te tratan mal ni mucho menos"), sen deixar de enfatizar por iso o valor en termos de verdade do seu relato: "sí no es lo mismo". A "desconfianza", segundo I1, non se sitúa no trato, tamén non aporta testemuños lingüísticos que sosteñan a existencia desta hipotética actitude dalgúns 
individuos face a ela; con todo, ela reitera "sí no es lo mismo", posicionándose na entrevista como alguén convicto do que está a dicir. Que realidade subxace á performance de I1?

Ocórrensenos varias posibilidades: a) que a imaxe preconcibida sobre o colectivo galegofalante imposta polos grupos dominantes ('os galegos son/somos desconfiados') está a operar na súa valoración,, b) que os interlocutores de que nos fala I1 perciben que ela non pertence á mesma comunidade de práctica e, por tanto, non a consideran lexítima, e c) que I1 asume unha identidade de inmigrante e está a espera dun determinado comportamento, de modo que acentúa esa identidade colocándose ela propia fóra da lexitimidade, quer reforzando a deslexitimación. De ser correcta a hipótese b), I1 estaríanos a falar dun proceso social envolvido nas dinámicas de negociación da identidade na interacción que Bucholtz e Hall (2005) asocian á dicotomía "autorización" / "ilexitimación", propios do principio relacional de que xa falamos. A informante dá sinais de que é consciente de como este binomio opera nos intercambios comunicativos con membros da súa(s) comunidade(s) de recepción: a "desconfianza" de que fala remite á concepción da alteridade como un suxeito ilexítimo, cuxa identidade pasa a ser "dismissed, censored, or simply ignored" (Bucholtz e Hall, 2005: 604). De ser correcta a interpretación c), e podendo aplicarse igualmente o exposto en termos de identidade para b), estariamos perante unha deslexitimación consciente no proceso de construción identitaria da inmigrante.

\section{Conclusións}

Ao longo deste artigo procuramos aproximarnos ao comportamento verbal dun grupo de estudantes de galego L2 en relación ao fenómeno da (des)cortesía pragmática. Así, tentamos acceder ás narrativas metapragmáticas (o que din que fan) de varios informantes procedentes de fóra da Galiza e á súa performance pragmática (o que efectivamente fan). Para este segundo propósito, tornouse necesario reflexionar igualmente acerca da conduta adoptada pola autora do traballo, en calidade de actora participante do intercambio comunicativo, no transcurso das entrevistas (sección 4.1.). A grandes trazos, o noso obxectivo consistiu en deitar luz á volta dos discursos que subxacen aos procesos de adquisición da lingua galega como L2 no que atinxe o nivel da (des)cortesía.
Quixemos, nun primeiro bloque (3.2, $3.3 \mathrm{e}$ 3.4), tratar os aspectos socionormativos ligados ás prácticas concebidas como corteses e descorteses de parte dos informantes. Viuse como estes indexan de forma explícita estas prácticas a través de etiquetas metapragmáticas: "muito respecto", "mui respectables", "mui respectuoso" (Exemplo 1); "respectuoso", "educado", "mantendo o respecto" (Exemplo 2); "tanto cuidado", "un respecto" (Exemplo 3); "moito máis directo", "máis bruto", "sen respecto" (Exemplo 4). Argumentamos que na base da produción deste tipo de metacomentarios -ben como das retóricas de vida en que o fenómeno da (des)cortesía emerxe vinculado a prácticas localizadas non só na comunidade de orixe dos informantes (Exemplos 1 e 2), como tamén na de recepción (Exemplo 4), ben como nalgún contexto sen concretizar (exemplo 3) - predomina a influencia do habitus, das expectativas socionormativas propias dun determinado grupo e da estereotipación, todas elas nocións sociolóxicas interligadas.

Ilustramos a relación entre (des)cortesía e habitus a partir da análise dos exemplos $1 \mathrm{e}$ 2 (3.2), en que o informante se identifica cun conxunto de prácticas, verbais e non-verbais, naturalizadas na súa conduta e máis ou menos ritualizadas, que remiten a un determinado modo de organización social. Esta idea foi ampliada a partir dunha interpretación do exemplo 3 (3.3), en que se esclareceu a correspondencia existente entre unhas determinadas variedades comunicativas (formas educadas) e a adecuación a valores ideolóxicos que a informante coloca en contraposición ao discurso da (des)cortesía formulado por Brown e Levinson (1978/1987) e reproducido pola entrevistadora. Finalmente, neste primeira parte do artigo, incidimos na importancia dos procesos de estereotipación que atinxen a "comunidade imaxinada" da Galiza (Álvarez Cáccamo 2000) e que interfiren nas valoracións sobre o que é considerado cortés e adecuado de parte dos informantes (3.4). De maneira implícita, a través das ideas expostas e defendidas nesta primeira parte do artigo, quixemos igualmente evidenciar o que hai de forza colectiva naquelas enunciacións ás que se lle asigna un determinado valor social ou sociolingüístico nun contexto histórico concreto, frente a posíbeis lecturas focadas no lado da creatividade individual, ligada ao desdobramento de estratexias de (des)cortesía.

Nun segundo bloque de informacións, reflexionamos a propósito da imaxe e da identidade 
en canto produtos das interaccións interculturais. Para isto, na sección 4.2 prestamos atención ás dinámicas interaccionais vinculadas á vulnerabilidade á imaxe e no punto 4.3, aproximámonos ao fenómeno dos malentendidos interculturais (Consello de Europa 2002) coa finalidade de despexar os factores que inflúen na súa aparición no transcurso das interaccións dos informantes canto suxeitos migratorios. $\mathrm{Na}$ análise do exemplo 6 (4.2), retomamos a noción de estereotipo e explicamos como a súa emerxencia nun contexto de prácticas interculturais crea as condicións necesarias para que se desencadeen tentativas de renegociación das identidades (étnicas e/ou nacionais, neste caso). Sostivemos que no xerme deste tipo de situacións se encontra tanto a vulnerabilidade á imaxe como un esquema de expectativas ideolóxicas contrarias ao discurso (que a receptora interpreta como sendo ideolóxico tamén) en que o tal estereotipo opera. Por último (4.3), a partir do discurso metapragmático articulado por I1 á volta das diferenzas e dos malentendidos intergrupais, comprobamos como a) o descoñecemento das convencións pragmalingüisticas propias da(s) comunidades(s) de práctica coas que os informantes entran en contacto na Galiza pode levar a situacións de incomprensión, como acontece no exemplo 7; mais tamén apuntamos a que b) os conflitos de imaxe poden ser entendidos como a continuación de discursos nos que a identidade é (co)construída en base ao eixo da semellanzaldiferenza (exemplo 8).

Como mencionabamos no inicio, o Marco Europeo de Referencia para as Linguas incide na importancia de estudar a (des)cortesía nas aulas de LE e L2, considerando a posibilidade de que distintas comunidades lingüísticas presenten convencións pragmalingüísticas e sociopragmáticas diverxentes con respecto ao empaquetamento dos significados relativos á imaxe dos interlocutores. Con todo, como fomos vendo, a multiplicidade de discursos e prácticas asociadas ao fenómeno da (des)cortesía responden non apenas á existencia da variación entre a L1 e a L2 dos informantes, senón tamén á influencia de factores ideolóxicos, identitarios, socioculturais e situacionais que son postos en funcionamento no momento da interacción. En consecuencia, na aula de linguas, o óptimo será adoptar unha abordaxe da (des)cortesía que se adecúe á natureza discursiva deste fenómeno. Isto non exclúe a necesidade de ensinar e aprender a (des)cortesía do punto de vista dos actos de fala, das estratexias comunicativas e das fórmulas lingüísticas ás que, por defecto, lle é asignado un determinado valor social nun contexto histórico dado. Porén, faise necesario (e adquire sentido dentro da lóxica do enfoque comunicativo) conciencializar os estudantes de que a aprendizaxe da (des)cortesía (e, en xeral, dunha lingua) debe partir dunha reflexión sobre as prácticas comunicativas herdadas historicamente e sobre o propio posicionamento identitario a respecto da comunidade ou grupo ao cal se pretende acceder. En contrapartida, será tarefa do profesor incentivar este tipo de reflexión e proporcionar ao alumnado ferramentas que permitan guiala en forma de recursos didácticos.

Relativamente á posibilidade de dar continuidade a esta liña de investigación, unha proposta interesante sería a realización dunha análise cualitativa dos aspectos sociodiscursivos ligados ao fenómeno da (des)cortesía e da imaxe social presentes nos manuais de galego L2 existentes (nomeadamente, os Aula de Galego 1,2, 3 e 4).

\section{Referencias bibliográficas}

Álvarez Cáccamo, Celso (2000): Identidad, clase e ideologías lingüísticas en el discurso público gallego [Mareas Vivas y el nuevo orden sociolingüístico de clase]. Traballo presentado no IV Congreso de Lingüística General ( Cádiz, 3-6 de abril de 2000), na sesión "Ideologías y prejuicios lingüísticos" (coorgs. L. Martín Rojo e C. Álvarez Cáccamo), https://cutt.ly/bhOLvVX.

Austin, John Langshaw (1962): How to do things with words. Oxford: Oxford University Press (The William James Lectures).

Bourdieu, Pierre (1991): Language and Symbolic Power. Cambridge: Polity Press.

Brown, Penelope e Stephen C. Levinson (1987): Politeness: some universals in language usage. Cambridge: Cambridge University Press (Studies in Interactional Sociolinguistics).

Bucholtz, Mary e Kira Hall (2005): "Identity and Interaction: A Sociocultural Linguistic Approach", Discourse Studies 7, pp. 585-614, http://bucholtz.linguistics.ucsb.edu/sites/secure.lsit.ucsb.edu.ling.d7_b/ files/sitefiles/research/publications/BucholtzHall2005-DiscourseStudies.pdf.

Chamorro, Margarita; Ivonete da Silva e Xaquín Núñez (2008a): Aula de galego 1: curso de galego. Santiago de Compostela: Xunta de Galicia. Secretaría Xeral de Política Lingüística. 
(2008b): Aula de galego 4: curso de galego. Santiago de Compostela / Barcelona: Xunta de Galicia. Secretaría Xeral de Política Lingüística.

(2009a): Aula de galego 2: curso de galego. Santiago de Compostela: Xunta de Galicia. Secretaría Xeral de Política Lingüística.

(2009b): Aula de galego 3: curso de galego. Santiago de Compostela / Barcelona: Xunta de Galicia. Secretaría Xeral de Política Lingüística.

Consello de Europa (2002): Quadro europeu comum de referência para as línguas: aprendizagem, ensino, avaliação. Porto: Asa, http://area.dge.mec.pt/gramatica/Quadro_Europeu_total.pdf.

Culpeper, Jonathan (1996): "Towards an anatomy of impoliteness", Journal of Pragmatics 25/3, pp. 349-367.

Eckert, Penelope e Sally McConnell-Ginet (1992): "Think Practically and Look Locally: Language and Gender as Community-Based Practice", Annual Review of Anthropology 21/1, pp. 461-488.

Eelen, Gino (2001): A critique of politeness theories. Manchester / Northampton: St. Jerome Publishing.

Escandell-Vidal, Victoria (1996): "Towards a cognitive approach to politeness", Language Sciences 18/3-4, pp. 629-650.

Fernández López, Xemma (2009): “Interferencias pragmáticas: aproximación ás estratexias de cortesía nas peticións en galego", Revista Galega de Filoloxía 9, pp. 75-113.

Fidalgo Francisco, Elvira (2007): Niveis de competencia en lingua galega: descrición de habilidades e de contidos adaptados ao Marco europeo común de referencia para as linguas. Santiago de Compostela: Xunta de Galicia.

Fraser, Bruce (1990): "Perspectives on politeness", Journal of Pragmatics 14/2, pp. 219-236.

Goffman, Erving (1967): Interaction ritual: essays on face-to-face behavior. Garden City: Doubleday.

Grice, H. Paul (1975): "Logic and conversation”, Syntax and Semantic 3, pp. 45-58.

Holmes, Janet (1995): Women, men and politeness. London: Longman.

Kasper, Gabriele (1990): “Linguistic politeness”, Journal of Pragmatics 14/2, pp. 193-218.

Lakoff, Robin Tolmach (1973): “The logic of politeness, or Minding your P's and Q's”, en L. A. Sutton (ed.) (2017): Context counts: papers on language, gender, and power. Nova York: Oxford University Press, pp. 37-51, https://books.google.pt/books?id=hdc-DgAAQBAJ.

Leech, Geoffrey N. (1983): Principles of pragmatics. London: Longman.

(2007): "Politeness: Is there an East-West Divide?", Journal of Politeness Research. Language, Behaviour, Culture, 3/2, pp. 167-206.

Locher, Miriam A. (2004): Power and politeness in action : disagreements in oral communication. Berlin / New York: Mouton de Gruyter.

(2008): "Handbooks of Applied Linguistics", en Gerd Antos, Eija Ventola e Tilo Weber (eds.): Handbook of Interpersonal Communication. Berlin / New York: Mouton de Gruyter, pp. 509-540, https://edoc.unibas.ch/15408/4/20131011105559_5257bd1fb8541-000.pdf.

Locher, Miriam A. e Richard J. Watts (2005): "Politeness Theory and Relational Work", Journal of Politeness Research. Language, Behaviour, Culture 1/1, DOI: https://doi.org/10.1515/jplr.2005.1.1.9.

Mills, Sara (2003): Gender and politeness. Cambridge: Cambridge University Press.

(2015): "Language, Culture, And Politeness", en Farzad Sharifian (ed.): The Routledge Handbook Of Language And Culture. Nova York: Routledge.

Scollon, Ron e Suzanne Wong Scollon (2001): Intercultural communication: a discourse approach. Oxford: Blackwell.

Tracy, Karen (1990): “The many faces of facework", en Handbook of language and social psychology. Oxford: John Wiley \& Sons, pp. 209-226.

Watts, Richard J. (2005): “Linguistic politeness research: Quo vadis?”, en Richard J. Watts, Sachiko Ide e Konrad Ehlich (eds.): Politeness in Language. Studies in its History, Theory and Practice. Berlin: Mouton de Gruyter, pp. xi-xiv, http://media.ebook.de/shop/coverscans/161PDF/16102665_lprob_1.pdf.

(2003): Politeness. Cambridge: Cambridge University Press.

Watts, Richard J., Sachiko Ide e Konrad Ehlich (2005): "Introduction", en Richard J. Watts, Sachiko Ide e Konrad Ehlich (eds.), Politess in Language: Studies in its History, Theory and Practice. Berlin: Mouton de Gruyter, pp. 1-18, https://books.google.pt/books?id=OopHpWKZ6WMC.

Werkhofer, Konrad T. (1992): "Traditional and modern views: the social constitution and the power of politeness", en Richard Watts et al. (eds.): Politeness in Language: Studies in its history, theory and practice. Berlín / Nueva York: Mouton de Gruyter, pp. 155-199. 
Wittenburg, Peter; Hennie Brugman, Albert Russel, Alexander Klassmann e Han Sloetjes (2006): "ELAN: a Professional Framework for Multimodality Research", en Proceedings of the Fifth International Conference on Language Resources and Evaluation, LREC 2006 (Genoa, Italy, May 22-28, 2006), pp. 1556-1559, http://www.lrec-conf.org/proceedings/lrec2006/pdf/153_pdf.pdf.

\section{Anexo I}

\begin{tabular}{l|l|l|l|l|l|l|}
\hline \multicolumn{1}{|l|}{ Informante } & Xénero & Idade & \multicolumn{1}{|c|}{ L1 } & \multicolumn{1}{|c|}{ Procedencia } & \multicolumn{1}{|c|}{ Orixe } & $\begin{array}{c}\text { Permanencia } \\
\text { en Galiza }\end{array}$ \\
\hline I1 & M & 31 & Español & Urbana & Venezuela & 6 anos \\
\hline I2 & H & 46 & Español & Urbana & Andalucía & 18 meses \\
\hline I3 & H & 36 & Basco/ Español & Urbana & Guipúscoa & 3 anos \\
\hline I4 & H & 38 & Galego/Espanhol & Rural & Galiza & Universitarios \\
\hline I5 & M & 42 & Español & Urbana & Mar de Plata & 12 anos \\
\hline I6 & H & 49 & Maia/Español & Urbana & Guatemala & Universitarios \\
\hline E & M & 26 & Galego/Espanhol & Rural & Coristanco (Galiza) & 25 anos \\
\hline
\end{tabular}

Táboa 1: Datos relativos ao perfil sociolingüístico dos informantes. Informacións obtidas en abril de 2018 
